\title{
PRINCÍPIOS DO ENSINAR-APRENDER GEOGRAFIA: APONTAMENTOS PARA A RACIONALIDADE DO COMUM
}

\author{
Eduardo Donizeti GIROTTO ${ }^{1}$ \\ Ana Cláudia Carvalho GIORDANI²
}

\begin{abstract}
RESUMO
O presente artigo discute princípios para ensinar-aprender geografia na escola pública, reconhecendo e problematizando o contexto de ampliação das desigualdades e violação de direitos que têm marcado o projeto societário neoliberal no Brasil. Parte importante deste contexto acentua-se com a emergência de políticas educacionais que pouco problematizam as desigualdades da educação pública no Brasil, reproduzindo-as, com o intuito de consolidar lógicas privatistas em torno das escolas, dos campos disciplinares, da docência e da educação. Os princípios apresentados neste texto se fundam na busca de uma outra racionalidade para além da lógica neoliberal. Para tanto, dialogamos com o conceito de comum, sistematizado por Dardot \& Laval (2018), discutindo os sentidos do ensinar-aprender geografia como momento de construção desta outra racionalidade. Em nossa perspectiva, diante da hegemonia da racionalidade neoliberal, é fundamental construir o comum desde as escolas, reinventando nossas práticas, reconhecendo as geografias que fazemos, em diferentes contextos e que, reunidas, tecem novas grafias a muitas mãos e abrem as possibilidades das ações em defesa de um outro projeto societário.
\end{abstract}

Palavras-chave: Ensinar-aprender Geografia. Comum. Neoliberalismo.

\section{TEACHING-LEARNING GEOGRAPHY PRINCIPLES: NOTES ON THE RATIONALITY OF THE COMMON}

\begin{abstract}
This article discusses principles for teaching-learning geography in the public school, recognizing and problematizing the context of widening inequalities and violation of rights that have marked the neoliberal societal project in Brazil. An important part of this context is accentuated by the emergence of educational policies that little problematize the inequalities of public education in Brazil, reproducing them, in order to consolidate privatist logics around schools, disciplinary fields, teaching and education. The principles presented in this text are based on the search for another rationality beyond neoliberal logic. Therefore, we dialog with the concept of common, systematized by Dardot \& Laval (2018), discussing the meanings of teaching-learning geography as a

\footnotetext{
1 Professor do Departamento de Geografia da Universidade de São Paulo. Coordenador do Laboratório de Ensino e Material Didático e membro da Rede Escola Pública e Universidade. E-mail: egirotto@usp.br.

2 Professora do Departamento de Geografia da Universidade Federal Fluminense. E-mail: aninhagiordani@gmail.com.
} 
moment of construction of this other rationality. From our perspective, in the face of the hegemony of neoliberal rationality, it is fundamental to build the common from schools, reinventing our practices, recognizing the geographies we make in different contexts and which, together, weave new spellings into many hands and open the possibilities of actions. in defense of another corporate project.

Keywords: Teach-learn geography. Common. Neoliberalism.

\section{INTRODUÇÃO}

A instituição de políticas educacionais pode acionar recomposições sociais profundas. A recente aprovação de reformas educacionais, mais especificamente a Reforma do Ensino Médio lei 13.415/17, e a Base Nacional Comum Curricular, bem como os discursos de algumas das principais autoridades do país, tem acentuado o debate sobre os sentidos das humanidades na educação. Em certa medida, tais ações têm construído as condições para que se deslegitime o lugar que tais conhecimentos ocupam nos currículos oficiais, acusando-os, de um lado, de fazerem parte de um amplo projeto político "de doutrinação de esquerda”, de outro, de estarem desarticulados das necessidades da dinâmica produtiva do mundo contemporâneo.

Como parte das humanidades, a geografia, enquanto campo do conhecimento, não tem passado incólume por este processo. Vale destacar que, na história do desenvolvimento deste campo do conhecimento, está presente uma continua ambiguidade, bem descrita no célebre trabalho de Yves Lacoste, que pode ser resumida da seguinte forma: como conhecimento estratégico, historicamente vinculado a processos de controle e domínio territorial, a Geografia, como disciplina, ainda é amplamente acusada de ser, nos termos propostos por Lacoste, enfadonha e desinteressante, pouco fazendo sentido para muitos estudantes que, com ela, lidam diariamente. Portanto, a geografia na escola sofre uma dupla acusação, aparentemente contraditória: é acusada, por alguns grupos políticos, de doutrinação (marxista, de esquerda etc.) e vista, pela maioria dos estudantes, como um conhecimento que pouco ou nada dialoga com suas vidas. Como lidar com este quadro? 
Em nossa perspectiva, uma das saídas para enfrentá-lo passa pela reconstrução dos sentidos e princípios de ensinar-aprender geografia nos tempos atuais no Brasil. Para tanto, é fundamental problematizar o contexto de ampliação das desigualdades e violação de direitos que têm marcado o projeto societário neoliberal no Brasil. Parte importante deste contexto acentua-se com a emergência de políticas educacionais que pouco problematizam as desigualdades da educação pública no Brasil, reproduzindo-as, com o intuito de consolidar lógicas privatistas em torno das escolas, dos campos disciplinares, da docência e da educação. Em contrapartida, os princípios apresentados e defendidos neste texto se fundam na busca de uma outra racionalidade para além da lógica neoliberal. Para tanto, dialogamos com o conceito de comum, sistematizado por Dardot \& Laval (2018), discutindo os sentidos do ensinaraprender geografia como momento de construção desta outra racionalidade. Trata-se, portanto, de problematizar, construindo um diálogo entre a denúncia e o anúncio, se ainda faz sentido reivindicar a docência em geografia como um ato de criação e o raciocínio geográfico como processo fundamental para a formação de sujeitos capazes de pensar a si mesmos na relação com os outros e com o mundo em diferentes escalas espaço-temporais. Este é o principal objetivo deste artigo.

Para tanto, dividimos o texto em dois momentos. No primeiro deles, debatemos os contextos do ensinar-aprender geografia no Brasil atual, discutindo as possíveis implicações dos avanços da precarização do trabalho sob a lógica neoliberal, da acumulação por espoliação de direitos e da permanência dos genocídios como características fundantes da formação socioespacial brasileira sob o modo de produção capitalista. No segundo momento, discutimos os princípios para pensar o ensinar-aprender geografia diante deste contexto. Por fim, discutimos as possiblidades de tais princípios no sentido de pensar as possibilidades de subversão do ensinar-aprender geografia diante de situações-limites e da exigência de experienciar os inéditos viáveis (FREIRE, 1971). 


\section{PRECARIZAÇÃO, ESPOLIAÇÃO E GENOCÍDIO: FAZ SENTIDO ENSINAR-APRENDER GEOGRAFIA EM TEMPOS COMO ESTES?}

Partimos do pressuposto que todo o debate sobre educação é também um debate sobre sociedade. Isso significa dizer que não é possível entender as formas-conteúdos dos processos educativos sem levar em consideração as dinâmicas sociais que as produziram. Em nossa perspectiva, o conceito de formação socioespacial, desenvolvido por Santos (1978), é um importante ponto de partida para problematizarmos a relação entre educação e sociedade no Brasil.

Desde o início de século XV, vivemos, em diferentes escalas, o processo de formação do modo de produção capitalista. Tal processo não se deu de forma homogênea em todos os lugares, inclusive porque, em cada um destes lugares, diferentes povos organizavam suas formas de ser e pensar que não foram automaticamente apagadas a partir do desenvolvimento do capitalismo. Ao contrário, a força do lugar, no termo proposto por Santos, se revela nesta fusão entre diferentes escalas geográficas. Cada uma delas revela uma relação sociedade e natureza e suas sobreposições nunca são absolutas.

Portanto, tal compreensão, aponta para o desafio metodológico de compreender as especificidades do desenvolvimento do modo de produção capitalista no Brasil, neste território específico, marcado por singularidades anteriores ao capital, bem como pelos sentidos que cumpriu no desenvolvimento do capitalismo em escala mundial. Nestes termos, como um dos lugares em que se realiza a relação capitalista de produção, o território brasileiro precisa ser compreendido no interior destas relações complexas que não podem ser explicadas pela transposição de categorias e conceitos constituídos em outros contextos socioespaciais. Daí emerge a força do conceito de formação socioespacial, ao acentuar o que há de singularidade espacial do modo de produção capitalista no Brasil.

Em nenhum outro país foram assim contemporâneos e concomitantes processos como a desruralização as migrações brutais desenraizadoras, a urbanização galopante e concentradora, a expansão do consumo de massa, o crescimento econômico delirante, a concentração da mídia escrita, falada e televisionada, a degradação das escolas, a instalação de um regime repressivo como a supressão dos direitos elementares 
dos indivíduos, a substituição rápida e brutal, o triunfo, ainda que superficial, de uma filosofia de vida que privilegia os meios materiais e se despreocupa com os aspectos finalistas da existência e entroniza o egoísmo como lei superior, por que é o instrumento da buscada ascensão social. (SANTOS, 1987, p. 1213)

Assim, é fundamental destacar que a primeira característica marcante de nossa formação socioespacial, sob a lógica capitalista, é a violência, constituída, também, pela reprodução de genocídios. Fundado, primeiramente, no genocídio indígena, ocultado, muitas vezes, pelo discurso do "bom selvagem" e da "missão civilizatória" dos portugueses-bandeirantes, foi seguido por contínuos genocídios (das populações de origem africana, das mulheres, dos grupos LGBTQ). São genocídios porque afetam grupos sociais específicos, não se distribuindo de forma igual entre todos os sujeitos que habitam o território brasileiro. Não se trata, no entanto, de processo que se encerra no passado. Sua reprodução se mantém, cotidiana, em diferentes territórios do país.

Os dados mais recentes do Mapa da Violência do IPEA apontam que, nos últimos 5 anos, a média de assassinatos é de mais de 65 mil pessoas por ano. Destes, mais de 80\% são da classe trabalhadora, moradores de periferia, autodeclarados pretos e pardos. Em nossa perspectiva, tais dados reforçam a compreensão de que os genocídios ocupam lugar central em nossa formação socioespacial. Além disso, as políticas públicas não têm sido capazes, até aqui, de reverter este quadro. Ao contrário: o que temos visto é, sob a lógica neoliberal, tais políticas produzirem aquilo que Mbembe (2003, p.10) denominou de necropolítica, "formas de soberania cujo projeto central não é a luta pela autonomia, mas instrumentalização generalizadora da existência humana e a destruição material de corpos humanos e populações”.

Trata-se de ações deliberadas do Estado, por meio de diferentes mecanismos, dentre os quais as políticas públicas, de reproduzir ações de morte contra determinados grupos sociais, em determinados territórios. Segundo Butler (2018, p. 43)

Quais humanos contam como humanos? Quais humanos são dignos de reconhecimentos na esfera do aparecimento e quais não são? Que normas racistas, por exemplo, operam para distinguir entre aqueles que podem ser reconhecidos como humanos e os que não podem? 
Esta lógica da política pública está assentada também na compreensão do não-direito que tem marcado a nossa formação socioespacial. No caso brasileiro, como aponta Santos (1987), estamos diante de uma cidadania mutilada, na qual os consumidores mais-que-perfeitos solapam a possibilidade de realização dos direitos. Assentada em uma estrutura amplamente desigual (de acesso à saúde, educação, cultura, lazer, segurança), tal formação acentua os lugares de necropolítica. E o quadro se torna mais grave diante do avanço das diferentes políticas públicas recentes que espoliam os poucos direitos conquistados e expressos na Constituição Federal de 1988. As reformas trabalhista e da previdência, assim como a Emenda Constitucional do Teto de Gastos Públicos3 são exemplos destas políticas de espoliação que tem contribuído para ampliar a destruição do frágil sistema de seguridade social brasileira.

Como isso, vemos avançar novas modalidades de relações de trabalho que tem na precariedade uma de suas características principais. São relações de trabalho com pouca ou nenhuma segurança jurídica, com baixa remuneração e que colocam os trabalhadores em condições de menor capacidade de resistir aos avanços da espoliação dos direitos. Há que se destacar, no entanto, que a precariedade não pode ser lida como um processo novo na dinâmica da relação entre capital e trabalho. Como aponta Mattos (2019, p. 114)

A precarização como regra só pode ser vista como novidade se for abstraída a longa trajetória, da classe trabalhadora, desde o tempo de Marx. As possibilidades de diminuir o seu impacto sobre a experiência da classe trabalhadora dependeram sempre de condições histórias específicas, sob as quais a dinâmica desigual e combinada da expansão do capital e a luta de classes têm peso significativo.

Os avanços obtidos pelos trabalhadores em algumas partes do mundo, com especial destaque à Europa Ocidental, nos 30 anos posteriores a II Guerra Mundial, não podem ser tomados como condições comuns da classe trabalhadora no mundo. De forma geral, o trabalho assalariado, com regras, contratos e seguridade social, foi sempre restrito a um conjunto de

\footnotetext{
3 EMENDA CONSTITUCIONAL No 95, DE 15 DE DEZEMBRO DE 2016, que altera o Ato das Disposições Constitucionais Transitórias, para instituir o Novo Regime Fiscal, e dá outras providências.
} 
trabalhadores. A maioria, por sua vez, se deparou, constantemente, com a lógica da precariedade, o que leva a necessidade de atualizar o debate sobre o conceito de classe trabalhadora, compreendendo as suas diferentes formas-conteúdos, inclusive para construir as articulações e alianças necessárias para combater os mecanismos da precarização e da espoliação dos direitos.

Assim, como pensar os processos de ensinar-aprender geografia diante deste contexto de precarização, espoliação de direitos e genocídio que marca a dinâmica da formação socioespacial brasileira? As atuais políticas educacionais, como a Base Nacional Comum Curricular e a Reforma do Ensino Médio, dialogam com tal contexto ou, negando-o, contribuem para acentuá-lo? Como pensar uma docência em geografia que problematize, tensione, discuta e provoque os estudantes a construírem leituras geográfica do contexto em que vivem? A próxima seção deste texto busca fazer alguns apontamentos para pensarmos tais questões.

\section{O QUE FAZER? COMO RESISTIR E REINVENTAR O ENSINAR- APRENDER GEOGRAFIA}

Em nossa perspectiva, as respostas as perguntas anteriores pressupõem retomar, reconstruir e ressignificar princípios do ensinar-aprender geografia. A sistematização destes princípios se constitui em um esforço de traduzir em palavras, as ações que povoam as práticas pedagógicas desenvolvidas por docentes e pesquisadores nas escolas públicas brasileiras.

Mas o que é um princípio? Princípio é o que vem primeiro e fundamenta todo o resto. Não é um "início" que tenha a virtude de "apagar-se diante do que vem depois", ou simples "ponto de partida" que se deixaria definitivamente para trás, nunca mais voltando. É um verdadeiro começo, um "começo sempre a começar”, isto é, um começo que rege e domina tudo o que vem depois, (DARDOT; LAVAL, 2017) entendido, portanto, como elemento que dá sustentação para uma perspectiva, de uma posição diante de uma ideia, de um tema, de um campo, ou mesmo de uma ação. Isso significa que não utilizamos o termo princípio como algo que deve ser uma obrigatoriedade. Constitui uma questão política e não axiológica, de acordo com o pensamento de Paulo Freire. 
Como princípios, são transversais aos diferentes momentos do ensinaraprender geografia e precisam, a todo momento, serem revisitados, debatidos, postos em movimento em um diálogo que reconhece as escolas, os seus sujeitos e as geografias que fazem cotidianamente. Revelam também uma opção política dos autores e que pode ser expressa da seguinte forma: a escala de produção de política educacional contra hegemônica é a escola e o ponto de partir de qualquer debate curricular deve ser o projeto político-pedagógico e os seus sujeitos. Assim, coadunamos com os atos de currículo para alargarmos as concepções e as construções curriculares.

É fundamental ressaltar que não basta afirmar autonomias curriculantes, faz-se necessário, nessa altura das lutas por reconhecimento, direito e afirmação cultural na educação, mobilizar competências criadoras de autonomias emancipacionistas, fundamentadas em aportes filosóficos, epistemológicos, antropológicos, estéticos e políticopedagógicos, bem como inserções em práticas capazes de ajudar a empoderar atores sociais, sobretudo aqueles silenciados por uma educação historicamente autocentrada e excludente, tomando como problemática a distribuição social dos conhecimentos eleitos como formativos. Aliás, temos que admitir, ainda, que esse tem sido um solo fértil para que ideologias autocentradas plantem e cultivem suas perspectivas e cosmovisões, através de processos de naturalização e de hegemonização sociocultural do conhecimento presente na organização dos currículos e por consequência dos dispositivos formativos. (MACEDO, 2013, p. 428).

Portanto, os princípios aqui apresentados surgem da necessidade de, ao denunciar as políticas educacionais sob a lógica neoliberal que, ao conceber os indivíduos para a competição, para a flexibilidade, para o empreendedorismo e autoempresariamento, para o endividamento e para a despolitização4, ampliam a precarização, a espoliação dos direitos e os territórios de necropolítica, anunciar as escolas públicas como espaços de resistência e criação. Cabe, ao propormos princípios para ensinar-aprender Geografia, que os endereçamentos das leituras do mundo sejam para a racionalidade do comum, "a nova razão política que deve substituir a razão neoliberal” (DARDOT; LAVAL, 2017).

4 Veiga-Neto (2018). 


\section{$1^{\circ}$ PRINCÍPIO: A GEOGRAFIA COMO EXPERIÊNCIA ESPACIALMENTE REFERENCIADA}

A Geografia é uma experiência, no sentido proposto por Larrosa (2002), daquilo que nos acontece, que nos toca, nos transforma, que modifica o sujeito. Trata-se, no limite, de uma condição de existência dos sujeitos. Tal condição antecede a constituição da geografia como disciplina escolar e como campo científico, ocorrida, em diferentes partes do mundo, no século XIX. Em certa medida, o processo de transformação desta condição de existência em um campo de conhecimento se configura enquanto uma ação de disciplinamento, de normatização, de definição daquilo que é discurso competentemente instituído, nos termos propostos por Chauí (2002).

Ao reconhecer esta precedência da geografia como condição de existência dos sujeitos e sua anterioridade ao processo de formação do campo científico, buscamos acentuar a importância de um movimento de pesquisa que se assemelha a uma genealogia, nos termos propostos por Foucault (2005). Isso pressupõe retomar contextos, momentos, continuidades e rupturas que nos possibilitem compreender que relações podem ser estabelecidas entre a geografia como experiência e a geografia como ciência. Em nossa perspectiva, tal relação é fundamental, uma vez que se repõe a todo o momento nas salas de aula.

Como sujeitos de experiências, os estudantes levam, para a sala de aula, geografias. Na lógica bancária de educação (FREIRE, 1987), tais experiências são negadas e devem ser superadas pelo saber sistematizado exposto pelos docentes, o único válido. Na perspectiva dialógica, tais geografias produzidas pelos estudantes devem ser reconhecidas como mediações do processo de ensinar-aprender. Por isso, algumas questões nos parecem centrais: é possível um ensinar-aprender geografia que alargue as experiências dos estudantes? Como não fazer com que os meninos e meninas não percam suas geografias (LOPES, 2009) ao adentrarem os portões da escola? Ao mesmo tempo, não é preciso pensar um ensinar-aprender que amplie as geografias e experiências dos estudantes? 
Para isso, partimos da concepção de ensino-aprendizagem em geografia como ressignificação dos sentidos, em diálogo com o conceito de leitura de mundo de Paulo Freire.

Pensávamos numa alfabetização que fosse ao mesmo tempo um ato de criação, capaz de gerar outros atos criadores; uma alfabetização na qual o homem, que não é passivo nem objeto, desenvolvesse a atividade e a vivacidade da invenção e da reinvenção, características do estado de procura (FREIRE, 1971, p. 41)

Como ato de criação, o ensinar-aprender geografia pressupõe a mediação da palavra, nunca tomada como grafia vazia, desconectada do universo sensível dos sujeitos. A palavra é sempre social, histórica e espacialmente referenciada; expressa localizações e contextos, formas de ser e estar no mundo, trajetórias e geografias. Pela palavra, as representações e experiências dos estudantes se revelam e é possível construir mediações para o aprender que se constitui ato de pensamento.

Pensar é organizar o conhecimento e transformá-lo em ação, que pode ser fala ou ato, sendo que fala é ato. Pensamento é ação que transforma o pensador, o interlocutor e a relação entre os dois. Que passam ser a mesma pessoa (BOAL, 2009, p. 29)

Assim, reconhecer as geografias que os estudantes trazem, cotidianamente, para as salas de aula, colocando-as em diálogo com os saberes sistematizados neste campo científico, é refazer a relação fundante deste conhecimento, reinventando possibilidades de diálogo entre estas duas dimensões (como experiência e como ciência), inclusive para além dos limites estreitos do saber disciplinar, seja como currículo escolar, seja como campo científico.

\section{$2^{\circ}$ PRINCÍPIO: A GEOGRAFIA COMO CONDIÇÃo DO PROCESSO EDUCATIVO}

Para que o diálogo exposto no item anterior possa ocorrer, é fundamental um movimento metodológico: reconhecer a geografia da escola. O que temos visto a partir das políticas educacionais sob a lógica neoliberal é uma tentativa de ocultação do contexto socioespacial do processo educativo. Como aponta Azanha (2014), a primeira percepção que, como docentes, precisamos ter sobre 
a escola, é que ela possui um endereço. Significa afirmar que a localização de uma unidade escolar é um dos elementos importantes para a compreensão do contexto no qual os processos educativos irão ocorrer.

Tal contexto, por sua vez, não cumpre uma função estática, como pano de fundo, teatro das ações de estudantes, professores e comunidade. Tal contexto é produzido socialmente e é, nestes termos, expressão das contradições sociais que se revelam espacialmente (de classe, de raça, de gênero). O que significa ensinar-aprender geografia em comunidades ocupadas pelo tráfico ou alvo de ações polícias cotidianamente? Como ensinar-aprender geografia em meio a disparos de armas de fogo, em ruas que permanecem alagadas por mais de três meses, em lugares nos quais as violações dos direitos humanos são as regras e não as exceções?

É fundamental perceber que as políticas hegemônicas de educação pouco dialogam com esta geografia. Ao contrário, quando pensamos, por exemplo, nas políticas de avaliação padronizadas, o que temos é uma tentativa de neutralizar os contextos, amplamente desiguais e diversos, das unidades escolares brasileiras. Em certa medida, ao se assentarem em uma lógica meritocrática, que só faz sentido em um contexto no qual as oportunidades são, de fato, iguais para todos os sujeitos, tais avaliações buscam culpabilizar docentes e discentes pelo fracasso escolar, desresponsabilizando, por sua vez, o poder público e os agentes privados diretamente vinculados a elaboração e implementação de tais políticas.

Um exemplo desta lógica pode ser encontrado na propaganda divulgada pelo Ministério da Educação sobre a Base Nacional Comum Curricular. Na referida propaganda, são apresentadas as trajetórias de duas crianças de diferentes lugares do país, desde o momento em que acordam até chegarem na sala de aula de suas escolas. O discurso principal da propaganda afirma que, com a aprovação da Base Nacional Comum Curricular, todos os estudantes terão as mesmas oportunidades. No entanto, os dados do Censo Escolar de 2017 (Gráfico 1) estão muito distantes daqueles expressos nos discursos da propaganda oficial: 
Gráfico 1: Infraestrutura escolar, por rede de ensino, no Brasil (2017)

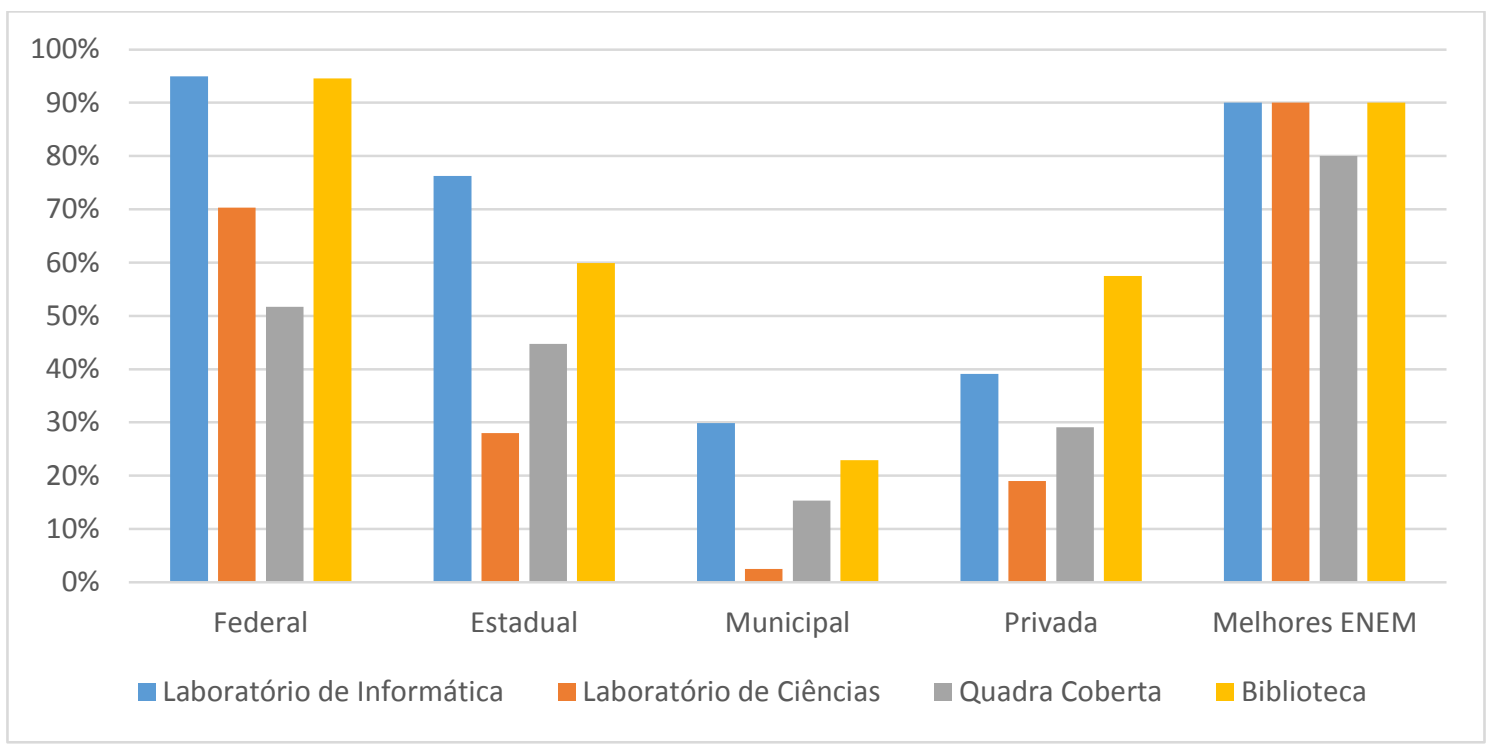

Fonte: elaborado pelos autores, a partir dos microdados do Censo Escolar / INEP (2017).

Neste sentido, tão importante quanto discutir a geografia na política educacional é discutir a geografia da política educacional. Durante a tramitação da Base Nacional Comum Curricular, muito tempo foi dedicado a se pensar quais conteúdos, conhecimentos, perspectivas teórico-metodológicas deveriam estar presentes em cada uma das versões do documento e pouco ao debate sobre as intencionalidades (espaciais, políticas, econômicas), a lógica geográfica de sua constituição que, no limite, reafirma o que Azanha (2011) denominou de abstracionismo pedagógico:

No estudo da escola brasileira, com raras exceções, as análises, por não se fundamentarem em cuidadosos e preliminares estudos descritivos, sugerem uma permanência a-histórica da instituição escolar, sendo por isso mesmo, incapazes de captar as efetivas transformações que ocorreram nas últimas décadas. $\mathrm{Na}$ verdade, a escola brasileira tem sido estudada como se fora uma entidade abstrata, completamente desligada de uma ambiência histórica (AZANHA, 2011, p. 45)

Reconhecer a geografia da escola é um dos elementos fundamentais para se reconhecer outras geografias: a dos estudantes, do currículo, da avaliação, dos conhecimentos e a própria geografia dos professores e professoras de geografia. Todas elas, em nossa perspectiva, cumprem uma função importante nas mediações didático-pedagógicas do ensinar-aprender geografia e não 
podem ser subsumidas em lógicas curriculares que busquem padronizar as singularidades espaciais. Tais lógicas, quando se realizam, contribuem para ampliar as desigualdades e não as desvendar, problematizar e, no limite, superá-las. São, portanto, momentos da reprodução dos espaços sem cidadãos, nos termos propostos por Santos (1987).

\section{$3^{\circ}$ PRINCÍPIO: A AULA DE GEOGRAFIA COMO ESPAÇO DE CRIAÇÃO E DE DISPUTA DA PROFISSÃO DOCENTE}

O reconhecimento dos princípios apontados anteriormente pressupõe uma mudança na relação que temos construído com a docência de forma hegemônica no Brasil, bem como um enfrentamento aos processos de precarização mais recentes. É importante destacar que tais processos estão assentados em uma lógica que concebe o trabalho docente como simples e, como tal, executado por quaisquer sujeitos, independentemente das condições de formação e atuação. Tais processos têm resultado em ataques à já frágil autonomia docente que, no Brasil, parece flutuar no limiar entre uma vocação, um dom, uma missão e uma semi-profissão.

Por trás desta perda de autonomia, reside a concepção de que não há um saber-fazer específico que justificaria a existência e o reconhecimento da profissão docente, uma vez que a transmissão de conteúdos, única e exclusivamente, seria o seu principal núcleo constituinte. Tal núcleo, por sua vez, pode ser encontrado em diferentes profissões, levando a ideia de que é possível substituir a formação por um processo de treinamento com o foco no desenvolvimento de habilidades e competências de transmissão de conteúdos. Além disso, é possível substituir, no limite, o docente por qualquer outro profissional que tenha passado por este treinamento.

Na lógica do trabalho docente como simples, políticas curriculares autoritárias como a Base Nacional Comum Curricular cumprem função essencial. Atrelada a base, tem sido produzido, recentemente, uma série de guias didáticos, semelhantes aos desenvolvidos na rede estadual de educação de São Paulo, que se assemelham aquilo que Apple (2000) denominou de currículos à prova de professores. Nestes guias, alguns deles distribuídos juntos com livros didáticos, os docentes podem encontrar aulas detalhadas, minuto a 
minuto, adequadas aos critérios da BNCC e que podem, segundo o discurso, ser reproduzidas em diferentes contextos. Todos os momentos da aula estão ali pensados e expressos, cabendo aos docentes o trabalho de execução. Em nossa perspectiva, é esta a concepção de docência induzida pela BNCC e que se atrela a um conjunto amplo de política de precarização do trabalho docente.

Cabe destacar as múltiplas dimensões da precarização do trabalho docente. Segundo Silva (2018, p. 24):

precariado professoral (um novo contingente do
professorado, cujas relações de trabalho estão mais próximas do
trabalho por tempo indeterminado e intermitente, modalidades
que não param de se expandir);
professorado estável-formal (professores concursados que
passam por diversas formas de precarização) e
a busca dos setores privatistas empresariais pela (con)formação
de um professorado subjetivamente adaptado
(professores concursados que atuam em escolas com parcerias
público-privadas buscando melhorar suas condições de
trabalho). (grifos da autora).

É contra esta concepção, com profundas implicações políticoepistemológicas, que nos colocamos, reivindicando a docência como profissão e a aula como espaço de criação, singular e irreprodutível. Tal reinvindicação coloca assento na complexidade da docência, constituída por um saber-fazerpensar-agir específico. Com isso, destacamos o lugar dos conhecimentos produzidos pelos professores e professoras da educação básica, a partir de diferentes contextos, ações e no diálogo com os sujeitos da educação, problematizando a relação entre o discurso competente que tem na universidade (e hoje, cada vez mais, no setor empresarial) lócus de produção e o processo de interdição dos discursos dos professores da educação básica. Em certa medida, na ordem epistemológica atual, as pesquisas acadêmicas e os relatórios do setor empresarial, estes últimos difundidos a partir de instituições como Todos pela Educação, Fundação Lehman, Instituto Airton Senna, entre outros, têm contribuído muito mais para silenciar do que reconhecer os sujeitos da educação, resultando assim em um processo de avanço da racionalidade técnico-científica nas políticas educacionais.

Por isso, diante deste contexto, é preciso reivindicar a aula como artesanal, irreprodutível, espaço de criação singular, momento fundamental 
para reinventar a profissão e disputar, politicamente, os sentidos do trabalho docente. Tal reivindicação é parte da luta política em defesa da docência como profissão, que se constrói em diferentes frentes de atuação: condições de carreira, formação, trabalho e jornada; remuneração, reconhecimento social, entre outros aspectos. É, nestes termos, ato político no enfrentamento das políticas neoliberais de educação que visam a constituição de uma docência alijada dos seus saberes e interdita em seus discursos. Retomar o direito de dizer sobre si é, em nossa perspectiva, um dos momentos de reivindicar o lugar da criação, da obra, da invenção no trabalho docente e de defesa da escola pública. Como como aponta Larrosa (2018).

há um professor quando se dão as formas de estar e as formas de fazer possível que aqui haja uma escola (e não uma fábrica, uma empresa, um shopping, um cárcere, uma praça, uma casa, um tribunal, uma igreja, um confessionário, um quartel, um sindicato ou um centro cultural). (LARROSA, 2018, p. 489).

\section{4o PRINCíPIO: A GEOGRAFIA NÃo SERVE PARA NADA. ELA PRODUZ SENTIDOS.}

Em seu clássico livro, Lacoste apresenta a concepção de uma ciência que serve, antes de tudo, para fazer a guerra e que pode, a partir de disputas e ressignificações, servir para pensar o espaço, para nele se organizar e combater. Apesar de concordarmos com os conteúdos da crítica que Lacoste estabelece acerca da relação entre a geografia dos professores e a geografia dos estados maiores, gostaríamos de apresentar um ponto de divergência. A geografia não deveria servir para nada.

Vivemos a hegemonia da racionalidade técnico-instrumental. Como aponta Larrosa,

O conhecimento é essencialmente a ciência e a tecnologia, algo essencialmente infinito, que somente pode crescer; algo universal e objetivo, de alguma forma impessoal; algo que está aí, fora de nós, como algo de que podemos nos apropriar e que podemos utilizar; e algo que tem que ver fundamentalmente com o útil no seu sentido mais estreitamente pragmático, num sentido estritamente instrumental. $O$ conhecimento é basicamente mercadoria e, estritamente, dinheiro; tão neutro e intercambiável, tão sujeito à rentabilidade e à circulação acelerada como o dinheiro. Recordem-se as teorias do capital 
humano ou essas retóricas contemporâneas sobre a sociedade do conhecimento, a sociedade da aprendizagem, ou a sociedade da informação (LARROSA, 2002, p. 27).

Nesta lógica, os currículos, os processos didáticos, as avaliações têm sido pensados à luz daquilo que serve e daquilo que não serve, em uma lógica de aplicação direta entre conhecimento, vida e produtividade. A avaliação da utilidade de um conhecimento tem sido feita a partir dos referenciais econômicos, reduzindo a ideia de formação ao acúmulo de capital humano (FRIGOTTO, 1990). A aprovação da reforma do ensino médio brasileiro, em 2017, expressa, em detalhes esta compreensão tecnicista de política educacional, com ênfase na ideia de que esta etapa da educação deve contemplar apenas aqueles conhecimentos que servem aos estudantes.

Por isso, imersos na lógica que busca reduzir as ações a sua dimensão técnico-instrumental, é fundamental fugir da armadilha que busca construir utilidades da geografia como forma de garantir o espaço epistemológico desta ciência nos currículos da educação básica. Ninguém porta conhecimento geográfico. Não é algo que se constitui de maneira externa aos sujeitos. Se, como conhecimento estratégico, continua a ser apropriado pelos diferentes agentes hegemônicos do mundo atual, é porque, nesta concepção de sociedade, interessa a reprodução da alienação geográfica, um dos fundamentos do modo de produção capitalista.

Defender a geografia como disciplina na escola pressupõe compreender os seus sentidos no processo de humanização, que é sempre, em nossa perspectiva, um processo de retomada da humanidade que nos é retirada, a todo momento, em uma sociedade marcada pela espoliação, precarização e genocídio. Nestes termos, concordamos com Gomes (2017): a geografia é uma forma de pensamento. Mas, como pensamento, é construção socialmente mediada. Por isso, é fundamental construir processos de ensinar-aprender geografia que possibilitem um movimento que vai da condição à consciência espacial. Não se trata de ação simples, uma vez que, historicamente, a alienação espacial é uma das alienações fundamentais do modo de produção capitalista e que ganha novos contornos com o avanço de tecnologias de controle espacial, amplamente presente na vida cotidiana de docentes e discentes. 
Mas, como saber potente, a geografia se reinventa, na própria capacidade dos sujeitos de reinventarem a vida, repleta de geografias. Como condição da existência, a geografia pode ser ensinada e aprendida como uma experiência de humanização, como momento de ruptura e de tensionamento com a lógica técnico-instrumental, como uma das formas de humanismo moderno, nos termos propostos por Monbeig em 1954. Frente a uma geografia enfadonha, desinteressante ou conteudista, que continua funcionar como invasão cultural, é preciso pensar a geografia como experiência. Como aponta Larrossa (2003, p. 24)

\begin{abstract}
A experiência, a possibilidade de que algo nos aconteça ou nos toque, requer um gesto de interrupção, um gesto que é quase impossível nos tempos que correm: requer parar para pensar, parar para olhar, parar para escutar, pensar mais devagar, olhar mais devagar, e escutar mais devagar; parar para sentir, sentir mais devagar, demorar-se nos detalhes, suspender a opinião, suspender o juízo, suspender a vontade, suspender $o$ automatismo da ação, cultivar a atenção e a delicadeza, abrir os olhos e os ouvidos, falar sobre o que nos acontece, aprender a lentidão, escutar aos outros, cultivar a arte do encontro, calar muito, ter paciência e dar-se tempo e espaço.
\end{abstract}

Assim, ampliar as possibilidades didáticas de ensinar-aprender geografia, dialogando com os sujeitos, seus contextos e suas demandas, sem que isso signifique aprisioná-los em si mesmos, pode contribuir para tecer novos sentidos à docência, a educação e a escola pública. Não se trata, no entanto, de reafirmar o individualismo de um saber medido por sua utilidade e aplicação técnico-instrumental, pressuposto da racionalidade neoliberal que se difunde nas diferentes políticas educacionais recentes. Construir, coletivamente, os sentidos da geografia que fazemos pode se configurar como importante momento para elaborar outros sentidos e projetos de mundo assentados na racionalidade do comum e que reconheçam os diferentes sujeitos, em suas singularidades e direitos, como plenos de potência criativa.

Para tanto, é imprescindível que coloquemos em discussão os próprios sentidos, que como docentes, atribuíamos ao ensinar-aprender geografia nos tempos atuais. Sem enfrentar tais questões, corremos o risco de reproduzir os mecanismos de alienação docente, tão amplamente induzidos pelas políticas educacionais. Por isso, o movimento aqui proposto de retomar princípios, 
pondo em questão o que somos, fazemos e criamos com docentes de geografia no diálogo com os estudantes e os lugares. Trata-se, nestes termos, de retomar, a todo momento, questões balizadoras do compromisso ético, político e profissional da docência: quais os sentidos da geografia que ensinamos e aprendemos? Qual a potência da aula de geografia como criação, da docência como invenção, da escola como momento de reinvindicação de nossas humanidades e da elaboração de outros projetos societários assentados no bem comum? Em nossa perspectiva, não deveríamos entrar em nossas salas de aulas, na escola e na universidade, desacompanhados destas questões, sem as quais, os espaços de alienação docente se consolidam. É na disputa cotidiana pelos discursos, narrativas e sentidos da profissão docente que construímos também a luta em defesa da educação pública como direito.

\section{CONSIDERAÇÕES FINAIS}

A escrita desse texto se deu no contexto de elaboração e implementação de um conjunto de reformas educacionais assentados na lógica neoliberal de educação em articulação com forças políticas conservadoras. Referimo-nos aqui a Base Nacional Comum Curricular, a Base Nacional Comum de Formação de Professores, ao Escola Sem Partido, aos processos de Homeschooling, a militarização das escolas, ao fechamento de turmas, de turnos e de escolas públicas. Deu-se também no acirramento das contradições que têm marcado a formação socioespacial brasileira sob o modo de produção capitalista, expressa na espoliação dos direitos, na precarização do trabalho e nos genocídios.

Este duplo contexto, articulado, nos mostra a necessidade de defesa de outros projetos de sociedade, de escola pública, de docência, das humanidades e de Geografia como caminhos para o comum enquanto princípio político (DARDOT; LAVAL, 2017). Os movimentos em torno do comum estão, mundialmente, em erupções, e lutam contra todas as formas de privatização da vida. As experiências recentes do Equador 5 e do Chile ${ }^{6}$ demonstram a força dos

\footnotetext{
5 Em outubro de 2019, diferentes movimentos sociais organizados, tomaram as ruas de inúmeras cidades do Equador contra uma série de medidas de austeridade fiscal impostas pelo governo do Presidente Lenín Moreno. Após 11 dias de greves e protestos, com ampla adesão popular e articulação dos grupos indígenas, as medidas foram suspensas.
} 
diferentes grupos organizados que apontam para os limites de um modo hegemônico de produção que espolia, mata, violenta, em diferentes aspectos e dimensões, os direitos dos seres humanos e da Terra. Ao mesmo tempo, tais movimentos colocam em xeque os limites da democracia como representação, reivindicando a ação direta, a participação, a consulta pública, a autonomia e a autogestão como outros princípios da ação política. Tais lutas e princípios, encontrados também nos diferentes movimentos de ocupação de escolas ocorridos no Brasil e em outros países da América Latina nos últimos anos, tensionam a necessidade de outras racionalidades, de reconhecimentos e práticas que se fundem no bem comum, na solidariedade, na equidade. São, assim, ações que, contra hegemonicamente, mantém a história aberta, ao denunciarem as contradições próprias da democracia liberal, do modo de produção capitalistas e dos seus sujeitos.

Assim, em nossa perspectiva, buscar princípios de ensinar-aprender Geografia na racionalidade comum torna-se urgente para, em diálogo com estes movimentos contra hegemônicos, possibilitar, desde a sala de aula e da escola pública, a constituição de outros discursos e sentidos para a educação contemporânea. Isso significa rechaçar a racionalidade neoliberal das políticas educacionais, expressas, por exemplo, na individualização dos percursos formativos propostos na Reforma do Ensino Médio que impõe norma de vidas baseadas na competição generalizada e na administração gerencial das desigualdades sociais. Concordamos com a concepção de Mbembe (2018) para o qual fabricar outras imagens de pensamento, "só seria possível com um longo e obrigatório aprendizado dos signos e das modalidades de seu reencontro com a experiência, o tempo próprio dos lugares da vida.” (MBEMBE, 2019, p. 11). Por isso, reafirmamos a necessidade da escola pública e das humanidades se constituírem como outras espacialidades e temporalidades para além da lógica neoliberal, como o intuito de possibilitar abertura aos atravessamentos cotidianos do ensinar-aprender Geografia na racionalidade do comum. Isso significada considerar as vibrações de expressões plurais advindas das margens

${ }^{6}$ Também em outubro de 2019, milhares de pessoas tomaram as ruas das principais cidades do Chile. Apesar do estopim ter sido o aumento das tarifas do metro, os protestos continuaram mesmo após a revogação da medida, tornando-se uma luta contra a precarização das condições de vida, trabalho e ampliação das desigualdades sociais no país. 
da sociedade e que se encontram na escola enquanto espacialidade de constituição de si, dos outros e do mundo.

Por isso, assumimos que há uma tonalidade política inegável nas espacialidades constituintes das experiências dos estudantes e dos docentes que ocupam, cotidianamente, as escolas (nos quilombos, nas favelas, nas tribos, nas comunidades ribeirinhas, nas florestas, nos campos, nas periferias) com seus corpos, vidas, condições, transbordando as multiplicidades de aprender-ensinar Geografia, irrompendo os limites estreitos das reformas curriculares neoliberais.

Assim, podemos entender que

[...] a experiência, e não a verdade, é o que dá sentido à educação. Educamos para transformar o que já sabemos, não para transmitir o já sabido. Se alguma coisa nos anima a educar é a possibilidade de que esse ato de educação, essa experiência em gestos, nos permita liberarmos de certas verdades, de modo a deixarmos de ser o que somos, para ser outra coisa para além do que vimos sendo. (LARROSA; KOHAN, 2014).

Destas experiências cotidianas, em defesa da educação como direito, da terra como vida, do trabalho como criação, que, em diferentes lugares, o comum é tecido, grafado na terra, reinventando geografias, reafirmando direitos, tensionando com os projetos de futuros que não podem ser reduzidos ao fatalismo neoliberal. E aqui, novamente, a escola pública, como lugar em que acabamos e no qual negociamos uma aqui e agora, comum e plural, nos termos propostos por Massey (2009), tem função central neste processo.

Construir o comum desde as escolas, reinventando nossas práticas, reconhecendo as geografias que fazemos, em diferentes contextos e que reunidas, tecem novas grafias a muitas mãos, se apresenta, em nossa perspectiva, como uma das principais ações em defesa de um outro projeto societário. Ensinar-aprender geografia, nestes termos, é um ato de rebeldia, de resistência e de reafirmação de direitos. É, enfim, um constante processo de humanização e da reafirmação da condição socioespacial dela, centrada na insuperável tarefa histórica de fazer da terra nosso mundo comum. 


\section{REFERÊNCIAS}

BOAL, A. A estética do oprimido. Rio de Janeiro: Garamond, 2009.

BRAGA, R. A política do precariado e a mercantilização do trabalho. Disponível: http://www.ihu.unisinos.br/entrevistas/516283-a-politica-doprecariado-e-a-mercantilizacao-do-trabalho Acesso em: set de 2019.

BUTLER, J. Corpos em aliança e a política das ruas. Rio de Janeiro: Civilização Brasileira, 2018.

DARDOT, P; LAVAL, C. A nova razão do mundo: ensaio sobre a sociedade neoliberal. Tradução de Mariana Echalar. 1. ed. São Paulo: Boitempo, 2016.

DARDOT, P; LAVAL, C. Comum: ensaio sobre a revolução no século XXI. Echalar. São Paulo: Boitempo, 2017.

FERNANDES, M. Aula de Geografia. Bagagem: Campina Grande, 2008. FOUCAULT, M. A ordem do discurso. $20^{\mathrm{a}}$ edição. São Paulo: Loyola, 2010. FOUCAULT, M. Em defesa da sociedade. São Paulo: WMF Martins Fontes, 2010.

FREIRE, P. Conscientização. São Paulo: Cortez, 1971.

LARROSA, J. Esperando não sei o quê: sobre o oficio de professor. Belo Horizonte: Autêntica, 2018.

LARROSA, J. Notas sobre a experiência e o saber de experiência. Revista Brasileira de Educação. nº 19, jan./ fev./ Mar/ 2002.

LARROSA, J. KOHAN, W. Experiência e sentido. IN: MASSCHELEIN, J.; SIMONS, M. Em defesa da Escola: uma questão pública. $2^{\circ}$ Ed. Belo Horizonte: Autêntica, 2014.

MACEDO, R. S. Atos de currículos: uma incessante atividade etnometódica e fonte de análise de práticas curriculares. Currículo sem Fronteiras, v. 13, n. 3, p. 427-435, set./dez. 2013.

MASEY, D. Pelo Espaço. Rio de Janeiro: Bertrand, 2009.

MASSCHELEIN, J.; SIMONS, M. Em defesa da Escola: uma questão pública. $2^{\text {a }}$ Ed. Belo Horizonte: Autêntica, 2014.

MATTOS, M. B. A classe trabalhadora: de Marx ao nosso tempo. São Paulo: Boitempo, 2019.

MBEMBE, A. Necropolítica. São Paulo: N-1, 2018. 
MBEMBE, A. Sair da Grande Noite: ensaio sobre a África descolonizada. Rio de Janeiro: Vozes, 2019.

MÉSZÁROS, I. A educação para além do capital. Tradução Isa Tavares. São Paulo: Boitempo, 2005.

SANTOS, M. O espaço do cidadão. Rio de Janeiro: Nobel, 1987.

SILVA, A. M. da. Tese (Doutorado em Educação). 2018. Dimensões da precarização do trabalho docente no século XXI: o precariado professoral e o professorado estável-formal sob a lógica privatista empresarial nas redes públicas brasileiras. Universidade Federal do Rio de Janeiro. Programa de PósGraduação em Educação. 395f.

SKLIAR, C. Del estar-juntos en educación y de los artificios de la convivencia, REU, Sorocaba, SP, v. 36, n. 1, p. 145-156, jun. 2010.

VEIGA-NETO, A. Neoliberalismo e educação: os desafios do precariado. IN: RESENDE, H. de (Org.) Michel Foucault: a arte neoliberal de governar a educação. São Paulo: Intermeios; Brasília: Capes/Cnpq, 2018.

VIGOTSKI, L.S. Desenvolvimento dos conceitos cotidianos e científicos na idade escolar. VIGOTSKI, L.S. Psicologia pedagógica. São Paulo: Martins Fontes, 2010.

Recebido em maio de 2019

Aceito em junho de 2019 